\title{
Investigation of Temperature Dependence of Polymer Gels for Use with Scanning Magnetic Resonance Imaging
}

\author{
Hiraku Kawamura1,2,3*, Kazuya Shinoda4, Hiraku Fuse1, Takaoki Takanashi², \\ Yoshikazu Shimada1, Yoshiyuki Ishimori', Masahiko Monma', Katsumi Miyamoto4, \\ Hitoshi Sato $^{1}$, Tatsuya Fujisaki' ${ }^{1}$ Takeji Sakae5 ${ }^{5}$, Akira Matsumura ${ }^{5}$ \\ ${ }^{1}$ Department of Radiological Sciences, Ibaraki Prefectural University of Health Sciences, Ibaraki, Japan \\ ${ }^{2} 3 \mathrm{D}$ Gel Dosimeter Research Laboratory, Innovation Center, RIKEN, 2-1, Hirosawa, Wako, Saitama, Japan \\ ${ }^{3}$ Faculty of Health Sciences, Tsukuba International University, Ibaraki, Japan \\ ${ }^{4}$ Department of Radiological Technology, Tsukuba Medical Center Hospital, Ibaraki, Japan \\ ${ }^{5}$ Graduate School of Comprehensive Human Science, University of Tsukuba, Ibaraki, Japan \\ Email: ^hiraku.kawamura@riken.jp
}

How to cite this paper: Kawamura, $\mathrm{H}$., Shinoda, K., Fuse, H., Takanashi, T., Shimada, Y., Ishimori, Y., Monma, M., Miyamoto, K., Sato, H., Fujisaki, T., Sakae, T. and Matsumura, A. (2018) Investigation of Temperature Dependence of Polymer Gels for Use with Scanning Magnetic Resonance Imaging. International Journal of Medical Physics, Clinical Engineering and Radiation Oncology, 7, 261-272.

https://doi.org/10.4236/ijmpcero.2018.72022

Received: March 22, 2018

Accepted: May 27, 2018

Published: May 30, 2018

Copyright (c) 2018 by authors and Scientific Research Publishing Inc. This work is licensed under the Creative Commons Attribution International License (CC BY 4.0).

http://creativecommons.org/licenses/by/4.0/

\begin{abstract}
Polymer gels are three-dimensional dosimetric tools. The purpose of the present study was to investigate the temperature dependence of polymer gels during scanning Magnetic Resonance Imaging. Prepared gels were irradiated with a $6 \mathrm{MV} \mathrm{X}$-ray beam at intensities ranging from 0 to $20 \mathrm{~Gy}$ in order to investigate their dose- $R_{2}$ and dose- $R_{1}$ responses. Irradiated gels were evaluated from 1.5-T magnetic resonance $\mathrm{R}_{2}$ and $\mathrm{R}_{1}$ images for each $5^{\circ} \mathrm{C}$ change in temperature from $5^{\circ} \mathrm{C}$ to $41^{\circ} \mathrm{C}$, and then the four-field box technique irradiation plan was used to deliver a total dose of $4 \mathrm{~Gy}$ using the same beam weight in each direction to the prepared gels. The profile of the dose map generated from the four-field irradiated gel data at $20^{\circ} \mathrm{C}$ was then compared with the planned data. The dose- $\mathrm{R}_{2}$ response curve was linear up to $20 \mathrm{~Gy}$ at $20^{\circ} \mathrm{C}$, with a slope of $1.17 \mathrm{~Gy}^{-1} \cdot \mathrm{s}^{-1}$. The slopes of the fitted curves of the dose- $\mathrm{R}_{2}$ decreased as gel temperature increased. The slopes of the dose- $R_{1}$ curves were more parallel than the slopes of the dose- $\mathrm{R}_{2}$ curves between 5 and $41^{\circ} \mathrm{C}$. The difference in the full width of half maximum of the gel profile data obtained using the four-field box technique at $20^{\circ} \mathrm{C}$ and the planned data were below $5 \%$ on average. The dose map from the irradiated gels obtained using the dose- $\mathrm{R}_{2}$ curve was the same as that from the planned data under the same temperature conditions. Measurement of difference between various temperatures is significant with dose accuracy. It is suitable to evaluate the gel dosimeter under the thermal equilibrium condition, MRI room temperature from the point of view of the stability of the irradiated gels.
\end{abstract}




\section{Keywords}

Polymer Gel Dosimetry, Temperature Dependence, MRI Scanning

\section{Introduction}

Polymer gels provide new three-dimensional (3D) dosimetric tools that hold promise for the 3D measurement of 3D doses during clinical radiotherapy, thus enhancing quality assurance. Radiotherapy is complex and requires precise monitoring [1]-[6]. Measurements using an ion chambers are precise, but an ion chamber is a point-detector, and thus is not suited to 3D dosimetry.

The clinical use of current polymer gel dosimeters faces several problems, including the temperature stability of polymer gels under irradiation and during dosimetric evaluation using Magnetic Resonance Imaging (MRI). Polymer gel dosimetry evaluated using MRI is conducted in low temperature environments because the gels melt at temperatures over approximately $25^{\circ} \mathrm{C}$, providing poor spatial information and inaccurate dosimetric results. Precise measurements of polymer gels in clinical settings are thus needed in order to determine the temperature dependence of polymer gels.

MRI is commonly used to evaluate the dose received by irradiated polymer gels. The spin-spin relaxation rate $\left(R_{2}=1 / T_{2}, s^{-1}\right)$ and spin-lattice relaxation rate $\left(R_{1}=1 / T_{1}, s^{-1}\right)$ provide the degree of polymerization of the irradiated gels and the radiation dose. This study investigated the dependence of $R_{2}$ on the dose received by polymer gels exhibiting a higher dose response than $R_{1}$. The fundamental properties of the temperature dependence of $R_{1}$ of polymer gels remain unknown. This study was designed to investigate the fundamental temperature effects on $R_{1}$ and $R_{2}$ by investigating the differences in temperature properties between the dose and $R_{1}$, and the dose and the $R_{2}$ calibration curve.

Several clinical irradiation studies using polymer gels have been conducted to date [6]-[13], but fundamental investigations of the temperature dependence of these gels are needed prior to the clinical application of gel dosimetry. To determine the feasibility of polymer gel dosimetry in clinical radiotherapy, we attempted to investigate the temperature-dependent properties of the polymer gels under simulated clinical irradiation conditions using a Radiation Treatment Planning System (RTPS).

\section{Materials and Methods}

\subsection{Gel Preparation}

BANG-3-type (Bis, Acrylamide, Nitrogen and Gelatin) polymer gels (BANG3PRO; MGS Research, Inc., Guilford, CT), and PAGAT (Polyacrylamide Gel and THPC) gels [14] were prepared. The BANG-3 type polymer gels were prepared using a BANG kit. The unmodified gel melted at $55^{\circ} \mathrm{C}$; thus, several additives were used [15]. PAGAT gels were prepared using $89 \% \mathrm{w} / \mathrm{w}$ water, $3 \%$ acryla- 
mide, $3 \% \mathrm{~N}, \mathrm{~N}^{\prime}$-methylenebisacrylamide (Bis), 5\% gelatin (300 bloom) and $5 \mathrm{mM}$ tetrakis (hydroxymethyl) phosphonium chloride (THPC). Gelatin was added to water, followed by heating at $50^{\circ} \mathrm{C}$ on a hot plate/magnetic stirrer. After the solution became clear, it was cooled to $45^{\circ} \mathrm{C}$ and Bis was added. After the Bis dissolved completely, THPC was added.

Prepared gels were poured into polyethylene-terephthalate (PET) vials and containers. Vials were $45 \times 30 \times 30 \mathrm{~mm}^{3}$ and were used for dose- $\mathrm{R}_{2}, \mathrm{R}_{1}$ calibration. Containers were $177 \times 74 \times 74 \mathrm{~mm}^{3}$ and were used to measure clinical irradiations by $3 \mathrm{D}$ dose distribution. Gels in the $\mathrm{PET}$ vials and containers were stored wrapped in aluminum foil in a refrigerator at $4^{\circ} \mathrm{C}$ until irradiation, as the gels melt at high temperature.

\subsection{Design of Gel Phantom for Specific Treatment Plan and Simulated Clinical Irradiation Studies}

Figure 1 shows a gel phantom using PAGAT gel for clinical irradiation. The phantom was $200 \times 140 \times 125 \mathrm{~mm}^{3}$, made of Styrofoam, and housed the gel container. The phantom was filled with water and then scanned in A-helical scan mode using an X-ray CT device (Aquilion LB; Toshiba Medical Systems, Tochigi, Japan) during the treatment plan. CT exposure conditions were as follows: tube voltage, $120 \mathrm{kV}$; tube current, $400 \mathrm{~mA}$; exposure time, $0.5 \mathrm{~s}$; slice thickness, $3.0 \mathrm{~mm}$; and imaging field of view, $550 \times 500 \mathrm{~mm}^{2}$. The number of slices per CT image was 70 .

Treatment plans were prepared using the RTPS system (Pinnacle ${ }^{3}$; Philips

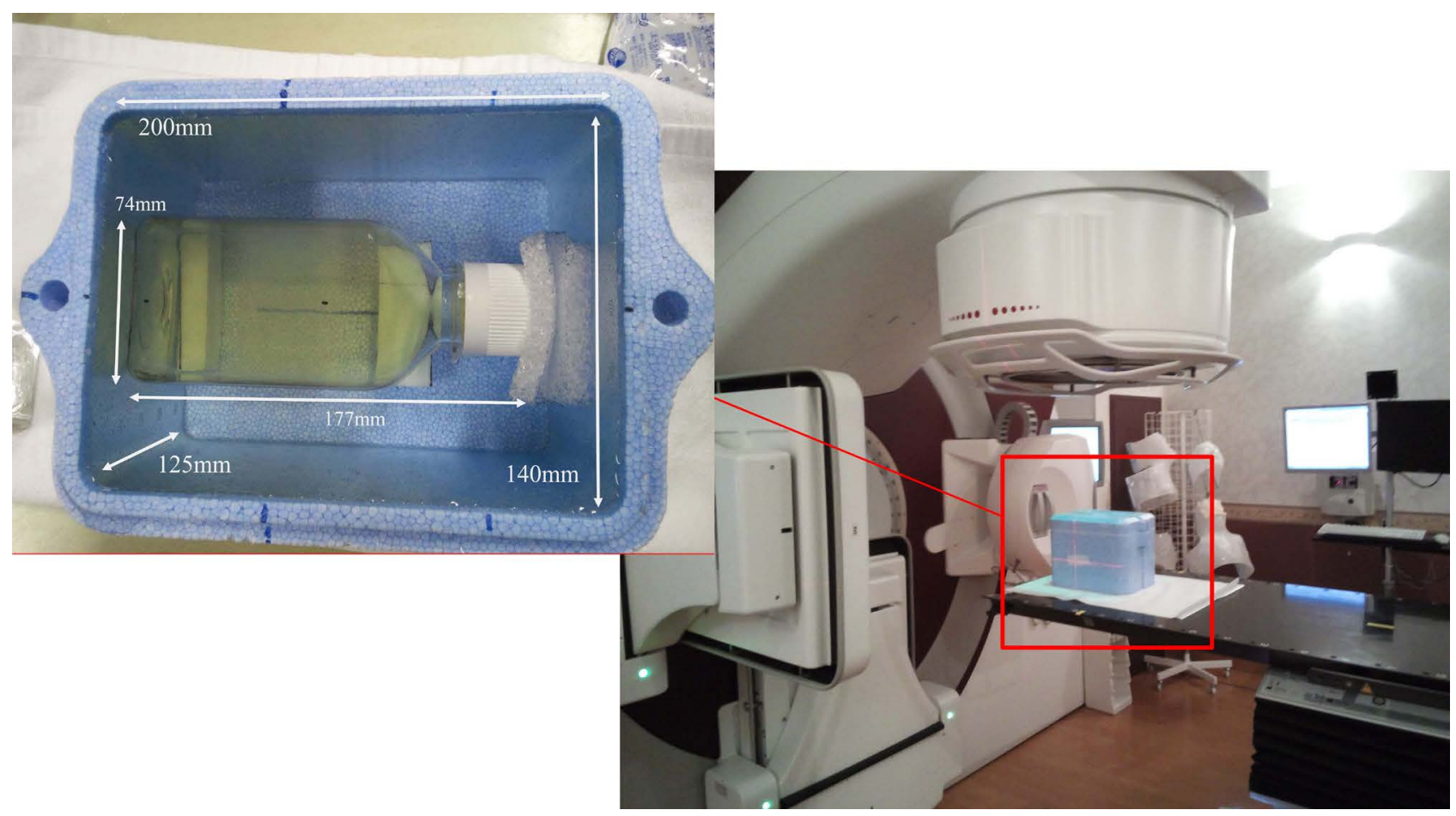

Figure 1. The photograph of gel phantom of the size $200 \times 140 \times 125 \mathrm{~mm}^{3}$ is shown. The PAGAT gel container was set on the gel phantom in the center position. The size of the PAGAT gel container is $177 \times 74 \times 74 \mathrm{~mm}^{3}$ (including neck). 
Healthcare, Andover, MA) and used a four-field box irradiation technique (Figure 2). The four-field box technique (crossfire) irradiation plan prescribed a total dose of $4 \mathrm{~Gy}$ and the same beam weight in each direction. The four beam irradiation calculations assumed the treatment of esophageal cancer and determined the dosimetric results of the polymer gel.

\subsection{Irradiation Using Photon Beams for Dose Calibration and Clinical Irradiation}

The prepared BANG-3-type gels and PAGAT gels were irradiated with a $6 \mathrm{MV}$ $\mathrm{X}$-ray beam on a linear accelerator (ELEKTA Synergy; ELEKTA, Stockholm, Sweden) at Tsukuba Medical Center Hospital.

Plan dose map (left, blue) was exported from RTPS and dose map from $\mathrm{R}_{2}$ image (right, red) was calculated from in-house program. This figure was shown that crossfire 4 beams irradiation calculations supposed that treatment of a esophageal cancer and dosimetric result of polymer gel using $6 \mathrm{MV}$ photon beam. The profiles between plan dose and dose map from $\mathrm{R}_{2}$ were compared.

First, the polymer gels in PET vials were irradiated with no collimator at the isocenter of a $300 \times 300 \times 300 \mathrm{~mm}^{3}$ water tank to calibrate the dose versus $\mathrm{R}_{2}$ and $\mathrm{R}_{1}$ from 0 to $20 \mathrm{~Gy}$ in the beam axis. After irradiation, gels were stored in a
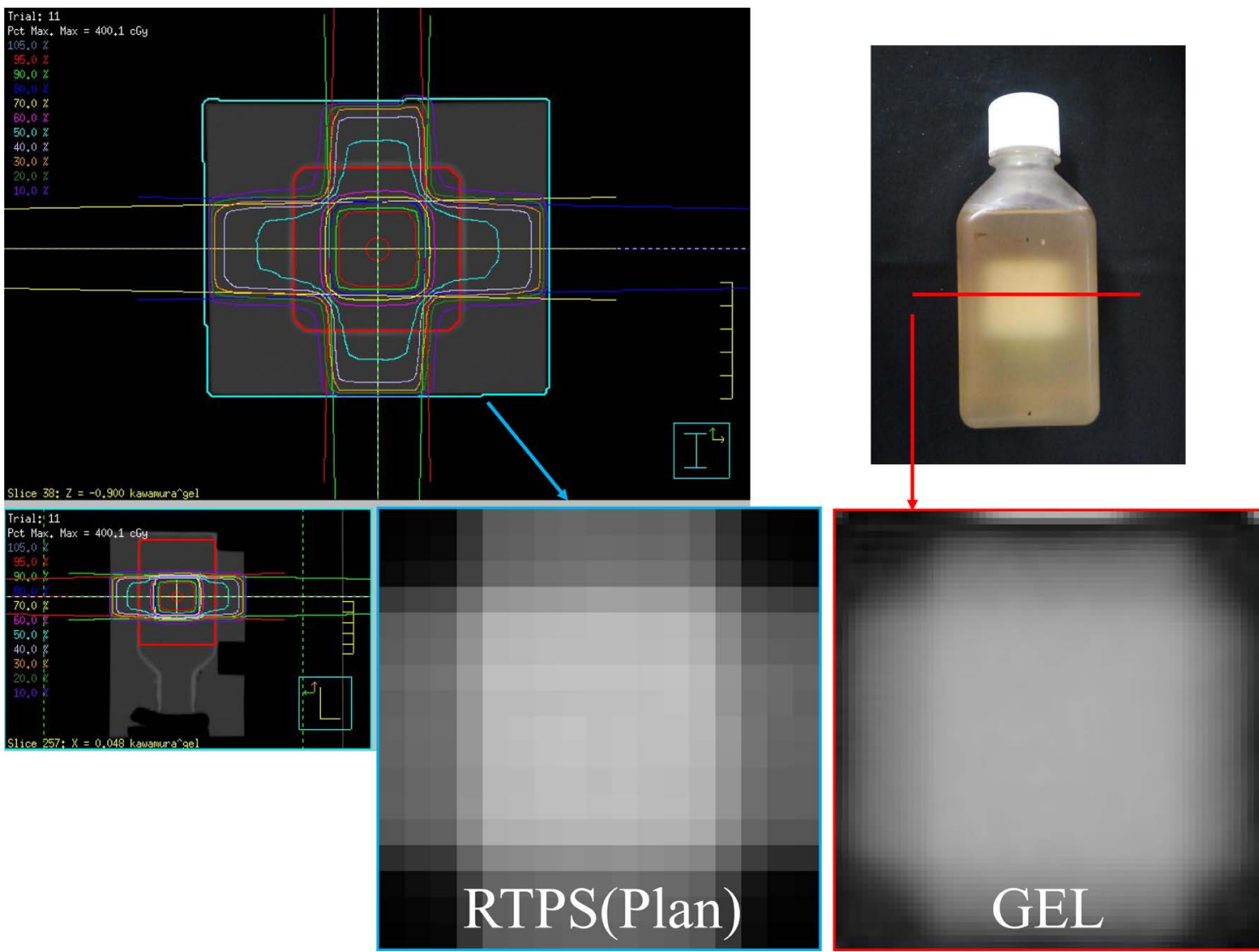

Figure 2. Treatment plan image was shown that four-field box technique. The sky blue box of the upper image was surrounded a gel phantom and the red box of all images was surrounded a gel container within fabricated polymer gels. Treatment plan was made by acquired X-ray CT images. 
refrigerator at $4^{\circ} \mathrm{C}$ until MRI scanning.

Second, gel phantoms were irradiated with $6 \mathrm{MV}$ X-ray beams at the isocenter in order to simulate clinical irradiation. The average dose rate was $300 \mathrm{MU} / \mathrm{min}$ (Figure 1).

\section{4. $\mathrm{R}_{1}$ and $\mathrm{R}_{2}$ Measurements Using MRI}

MRI measurements for dose evaluation of the gels were performed on a $1.5-\mathrm{T}$ Siemens AVANTO 1 day after irradiation. Irradiated gels were positioned in a quadrature (QD) coil for scanning.

For $\mathrm{R}_{2}$ measurements, gels were imaged using a multi-echo fast spin echo pulse sequence. Ten echoes of the sequence were used (echo time: TE $=15$ to $150 \mathrm{~ms}$; echo time interval, $15 \mathrm{~ms}$ ). For each scan, a repetition time (TR) of 1000 ms was used, with a $1 \mathrm{~mm}^{2}$ resolution (field of view $(F O V)=192 \mathrm{~mm}$, matrix number $=192 \times 192)$ using 5 -mm-thick planes. The obtained data were used to calculate $\mathrm{T}_{2}$ images using the MapIt program (Siemens) [16].

For $\mathrm{R}_{1}$ measurements, gels were imaged using a $3 \mathrm{D}$ volumetric interpolated breath-hold examination $(3 \mathrm{D}$-VIBE) sequence $(\mathrm{TE}=1.62 \mathrm{~ms}, \mathrm{TR}=15 \mathrm{~ms})$. For each scan, a resolution of $0.5 \mathrm{~mm}^{2}$ was used $(\mathrm{FOV}=192 \mathrm{~mm}$, matrix number $=$ $384 \times 384$ ) using 5 -mm-thick planes, the same as for $R_{2} . R_{1}$ and $R_{2}$ images was created to invert these pixel values using the original program.

The Styrofoam container described earlier was set in the QD coil and filled with water at $5.0^{\circ} \mathrm{C}$. Irradiated gel samples in vials and in containers were individually set in the center of the Styrofoam container and the water temperature in the container was raised from $5.0^{\circ} \mathrm{C}$ to $41.0^{\circ} \mathrm{C}$ at $5.0^{\circ} \mathrm{C} / \mathrm{min}$.

\section{5. $\mathbf{R}_{2}, \mathbf{R}_{1}$ versus Dose Linearity of the Polymer Gel Calibration Curve}

The obtained data were used to calculate $R_{2}$ images using the MapIt program. Two-dimensional (2D) $R_{1}$ and $R_{2}$ images were constructed from the $T_{1}$ and $T_{2}$ images using an in-house program. Data points for the dose $R_{2}, R_{1}$ characteristic curve were obtained by averaging the $\mathrm{R}_{2}$ values from the region of interest (ROI) in the polymer gel.

\subsection{Comparison between the RTPS Data and the $\mathbf{R}_{\mathbf{2}}$ and $\mathbf{R}_{\mathbf{1}}$ Images}

The acquired $R_{2}$ images were converted into dose images using calibration data from the dose- $R_{2}$ curve. Dose images from the $R_{2}$ images of the irradiated gels in the center profile were compared with the calculated plan data from the RTPS with four-box irradiation fields from the simulated clinical situation (Figure 2).

\section{Results}

\subsection{Temperature Dependency of $R_{2}$ versus Dose Linearity of the Polymer Gel Calibration Curve}

Figure 3 shows the $R_{2}$ values of the BANG polymer gels as a function of photon 
dose between 0 and $20 \mathrm{~Gy}$. Each $\mathrm{R}_{2}$ calibration curve was fit to a straight line for doses below $20 \mathrm{~Gy}$. The fitted straight line for photon dosimetry at $20^{\circ} \mathrm{C}$ had a gradient of $1.17 \mathrm{~Gy}^{-1} \cdot \mathrm{s}^{-1}$ and an intercept of $3.87 \mathrm{~s}^{-1}$, and the coefficient of correlation was 0.998 .

Figure 4 shows the $R_{2}$ values of the BANG polymer gels as a function of dose between $5.0^{\circ} \mathrm{C}$ and $40^{\circ} \mathrm{C}$. The fitted straight line of the data collected at $0 \mathrm{~Gy}$ provided a gradient of $-0.19^{\circ} \mathrm{C}^{-1} \cdot \mathrm{s}^{-1}$ and an intercept of $8.10 \mathrm{~s}^{-1}$, and fitting of the data collected at $20 \mathrm{~Gy}$ provided a gradient of $-0.96^{\circ} \mathrm{C}^{-1} \cdot \mathrm{s}^{-1}$ and an intercept of $47.45 \mathrm{~s}^{-1}$. The coefficient of correlation of the $0 \mathrm{~Gy}$ data was 0.894 and that of the 20 Gy data was 0.991 .

\subsection{Temperature Dependency of $R_{1}$ versus Dose Linearity of the Polymer Gel Calibration Curve}

Figure 5 shows the $R_{1}$ values of the BANG polymer gels as a function of photon doses between 0 and $20 \mathrm{~Gy}$. Each $\mathrm{R}_{1}$ calibration curve was fit to a straight line for

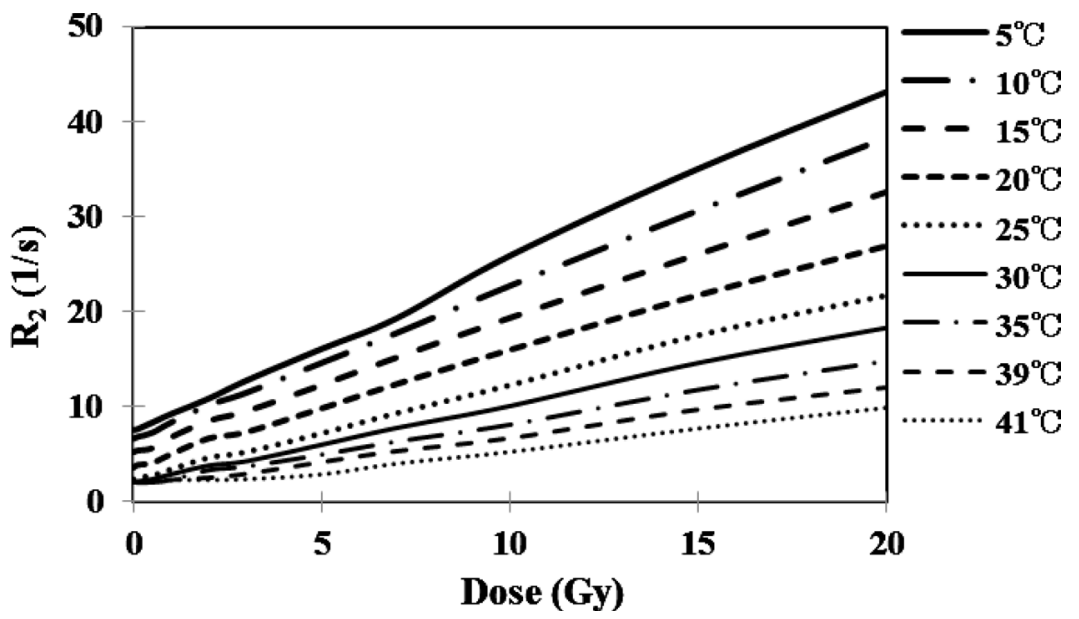

Figure 3. Dose- $\mathrm{R}_{2}$ responses using different temperature conditions. Error bars are omitted because of overlapping bars and plots.

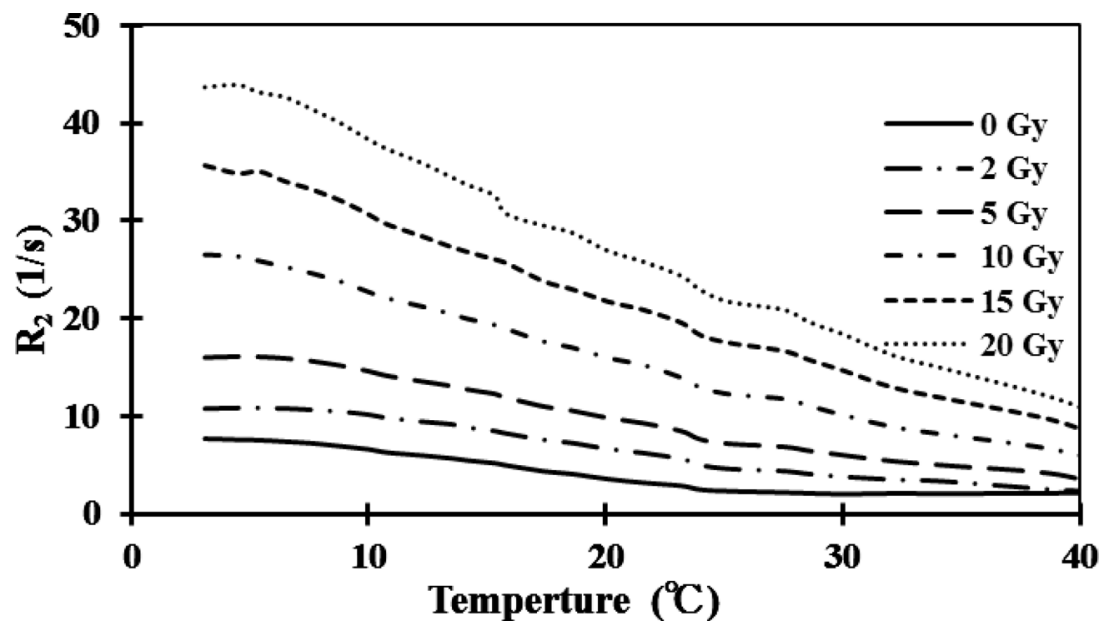

Figure 4. $\mathrm{R}_{2}$-temperture responses of the BANG-type gel dosimeter using different photon dose conditions. Error bars are omitted because of overlapping bars and plots. 
doses below 20 Gy. Data points were obtained by averaging the $R_{1}$ values in the polymer gel. The fitted straight line for data collected at $20^{\circ} \mathrm{C}$ had a gradient of $0.034 \mathrm{~Gy}^{-1} \cdot \mathrm{s}^{-1}$ and an intercept of $0.72 \mathrm{~s}^{-1}$. The coefficient of correlation was 0.962 .

Figure 6 shows the $R_{1}$ values of the BANG polymer gels as a function of dose between $5.0^{\circ} \mathrm{C}$ and $40^{\circ} \mathrm{C}$. The fitted straight line of the data collected at $0 \mathrm{~Gy}$ had a gradient of $-0.020^{\circ} \mathrm{C}^{-1} \cdot \mathrm{s}^{-1}$ and an intercept of $1.12 \mathrm{~s}^{-1}$, whereas the data collected at $20 \mathrm{~Gy}$ had a gradient of $-0.029^{\circ} \mathrm{C}^{-1} \cdot \mathrm{s}^{-1}$ and an intercept of $1.94 \mathrm{~s}^{-1}$. The coefficient of correlation of the 0 Gy data was 0.925 and that of the 20 Gy data was 0.985 .

The dose uncertainties (\%) of $R_{1}$ and $R_{2}$ between $5^{\circ} \mathrm{C}$ and $39^{\circ} \mathrm{C}$ are shown in Table 1. An increase in temperature results in large dose uncertainties of $R_{1}$ and $R_{2}$. The temperature-related errors in dose are $8.3 \%$ for $R_{1}$ and $7.5 \%$ for $R_{2}$. The dose-related error of the dose response results of the gel is below $8 \%$ at temperatures below $20^{\circ} \mathrm{C}$.

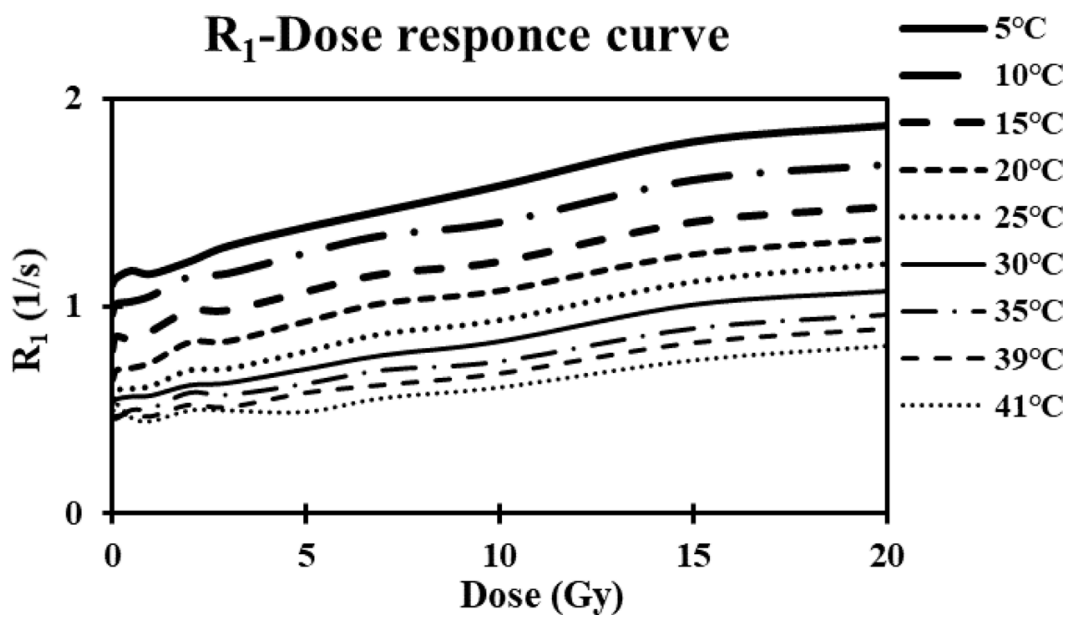

Figure 5. Dose- $\mathrm{R}_{1}$ response curves using different temperature conditions. Error bars are omitted because of overlapping bars and plots.

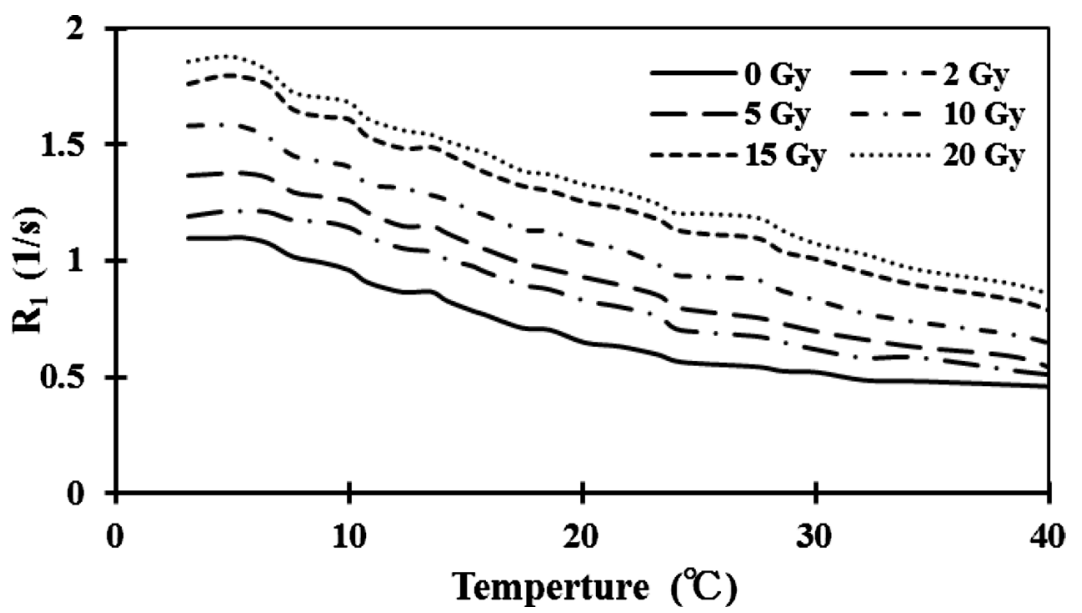

Figure 6. $\mathrm{R}_{1}$-temperture responses using different photon dose conditions. Error bars are omitted because of overlapping bars and plots. 
Table 1. Dose uncertainties (\%) of $\mathrm{R}_{1}$ and $\mathrm{R}_{2}$ between $5^{\circ} \mathrm{C}$ and $39^{\circ} \mathrm{C}$ from the dose response results.

\begin{tabular}{ccccccccc}
\hline & $\operatorname{TEMP}\left({ }^{\circ} \mathrm{C}\right)$ & 5 & 10 & 15 & 20 & 25 & 30 & 39 \\
\hline $\mathrm{R}_{1}$ & & 4.7 & 5.6 & 6.2 & 7.5 & 8.6 & 10.5 & 15.0 \\
$\mathrm{R}_{2}$ & & 6.1 & 6.1 & 6.1 & 7.2 & 8.5 & 8.2 & 10.2 \\
\hline
\end{tabular}

Dose uncertainties (\%).
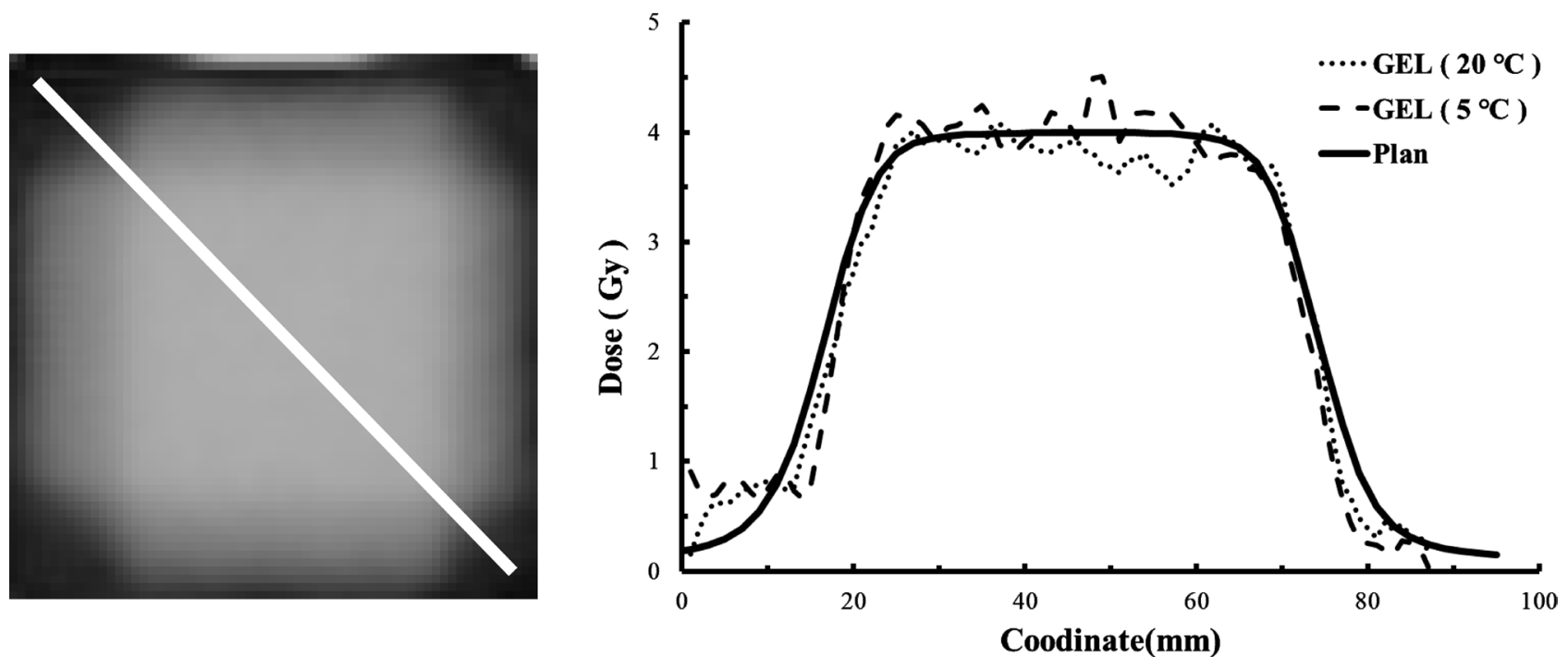

Figure 7. The dose profile (right) of the crossfire 4 beam-irradiated gels and the planned dose data. The profile of the gels is similar to that of the planned data.

\subsection{Dose Profile Comparison between Dose Images Obtained Using $\mathbf{R}_{2}$ Images of Polymer Gel and Dose Images Obtained Using RTPS}

Figure 7 shows the dose profile for PAGAT polymer gel on a planned RTPS of the oblique center line of the four-field box technique and planned data for comparison. The full width at half maximum (FWHM) of the GEL $\left(20^{\circ} \mathrm{C}\right)$, GEL $\left(5^{\circ} \mathrm{C}\right)$, and Plan (RTPS) curves were $57.48 \mathrm{~mm}, 55.22 \mathrm{~mm}$ and $58.48 \mathrm{~mm}$, respectively. The dose-related error of the results obtained using the gel at irradiation doses over $2 \mathrm{~Gy}$ at $20^{\circ} \mathrm{C}$ is $4.87 \%$ on average and the error at $5^{\circ} \mathrm{C}$ is $5.18 \%$ on average.

\section{Discussion}

\subsection{Temperature Dependency of $R_{2}, R_{1}$ versus Dose Linearity of the Polymer Gel Calibration Curve}

The results confirmed dose $R_{1}$ and dose $R_{2}$ linearity between 0 to 20 Gy. The dose- $R_{2}$ gradient was steeper at low temperature, as reported previously [10] [11]. Dose- $R_{1}$ curves with respect to temperature have not previously been reported and were found to parallel the dose- $\mathrm{R}_{2}$ gradient.

Dose gradient with temperature is less pronounced in the dose $R_{1}$ curves than in the dose $R_{2}$ curves and therefore the temperature dependence has less effect 
on dose $\mathrm{R}_{1}$ linearity than on dose $\mathrm{R}_{2}$ linearity. In contrast, the gradient of the $\mathrm{R}_{1}$ dose linearity was 40 times smaller than that of the $\mathrm{R}_{2}$ dose linearity. Furthermore, the overall standard deviation (SD) and coefficient of variation (calculated by dividing the $R_{2}$ or $R_{1}$ value by $S D$ ) of the $R_{1}$ images are larger than that of the $R_{2}$ images. The dose images obtained from the $R_{1}$ images included more noise when compared with the dose images obtained from the $\mathrm{R}_{2}$ images. Therefore, the dose images obtained from the $R_{1}$ images were less precise compared with the dose images obtained from the $\mathrm{R}_{2}$ images.

$\mathrm{R}_{2}$ and $\mathrm{R}_{1}$ are dependent on both the correlation time $\left(\tau_{c}\right)$ and the Larmor frequency $(\omega)$ from the Bloembergen-Purcell-Pound (BPP) relaxation theory [17] [18] [19]. $\tau_{c}$ of the gels shows an inverse correlation with their temperature: raising the temperature correspondingly decreases the $\tau_{c}$ of the gels. $\mathrm{T}_{1}$ and $\mathrm{T}_{2}$ are dependent on an inverse relationship with viscosity [17]. Here, I assumed that an increase in temperature decreased the viscosity of the gels. Therefore, the gel $R_{1}$ and $R_{2}$ values decreased as temperature increased, resulting in a larger $\tau_{c}$ and the gradients (Figure 4 and Figure 5) changed gradually with temperature. The change in the gradients of the dose $R_{2}$ curves was assumed to depend on both the viscosity of the gels arising from the degree of polymerization and the temperature.

\subsection{Dose Profile Comparison between Dose Images Obtained Using $\mathbf{R}_{2}$ and Dose Images Obtained Using RTPS}

The dose profile is presented in Figure 7 and shows differences in the temperature dependence and a comparison of the dose profile obtained by gel dosimetry and the RTPS plan. The dose images obtained from the $\mathrm{R}_{2}$ polymer gel data are precise regarding the process of conversion from the $R_{2}$ images to the dose image using the same temperature dose $\mathrm{R}_{2}$ curve. Because the prepared gels melt at high temperature, it was difficult to maintain the inside of the gels at a constant temperature as required during scanning MRI. Although BANG gels have a high $\mathrm{R}_{2}$ gradient, with changing temperature, they are less stable than PAGAT gels for the experiment to irradiated gels using RTPS. Methacrylic acid-based gel dosimeters such as BANG gel have the disadvantage of temperature dependency, in contrast to acrylic acid-based gel dosimeters such as PAGAT. BANG gels melt above $25^{\circ} \mathrm{C}$, while PAGAT gels melt at about $30^{\circ} \mathrm{C}$. At high and low temperatures, dose images were less precise and disagreed with the RTPS plan dose data. In this study, the dose-related error at irradiation doses over $2 \mathrm{~Gy}$ at $20^{\circ} \mathrm{C}$ was less than the error at $5^{\circ} \mathrm{C}$.

The difference in the FWHM of the dose profiles between the gels at $20^{\circ} \mathrm{C}$ and the RTPS plan dose data was $0.51 \mathrm{~mm}$, whereas at $5^{\circ} \mathrm{C}$, the difference was 1.8 $\mathrm{mm}$, despite the dose error of the dose response at low temperature being smaller than at high temperature, as shown in Table 1. The inhomogeneity related to the temperature of the irradiated gels in the containers may have caused the high dose error at low temperature. In addition, it is difficult to maintain a constant low temperature inside the gel phantom during MRI scanning and thus the 
temperature inhomogeneity inside the large phantom rose during exposure to the scanning RF pulse [20]. The temperature inhomogeneity resulting from RF exposure in a high field MRI scanner is large. Accordingly, dose evaluation using high field MRI scanning gives rise to data with large uncertainties. Dosimetric evaluation at MRI room temperature is required due to the stability of the scans during scanning MRI. Thus, it is necessary to maintain a constant at temperature inside the gels for precise measurements.

Future work will be aimed at clinical applications and will assess the temperature-related dose error using $\gamma$ analysis, dose differences, and distance-to-agreement measurements.

\section{Conclusions}

This study revealed the temperature dependency of polymer gel dosimeters during scanning MRI. Dose- $\mathrm{R}_{1}$ linearity and dose- $\mathrm{R}_{2}$ linearity were shown between 0 to $20 \mathrm{~Gy}$. These results indicate that temperature dependency has a greater effect on the gradient of the dose- $\mathrm{R}_{2}$ curves than the gradient of the dose- $\mathrm{R}_{1}$ curves.

Although the gradients of dose- $\mathrm{R}_{1}$ curves are more constant than the gradients of dose- $R_{2}$ curves, the $R_{1}$ dose images have more noises because of smaller dose gradients.

Comparison of the FWHM in the dose profile of dose images obtained using polymer gels at $20^{\circ} \mathrm{C}$ and using the RTPS plan data showed the difference to be below $5 \%$.

\section{Acknowledgements}

This work was supported by a Grant-in-Aid for Scientific Research (C) from the Japanese Society for the Promotion of Science and the Ministry of Education, Culture, Sports, Science and Technology of Japan (24601012).

We would like to thank Professor Shin-Ichiro Hayashi of the Department of Clinical Radiology, Faculty of Health Sciences, Hiroshima International University for fabricating the PAGAT gels.

\section{References}

[1] Baldock, C., De Deene, Y., Doran, S., Ibbott, G., Jirasek, A., Lepage, M., McAuley, KB., Oldham, M. and Schreiner, L.J. (2010) Polymer Gel Dosimetry. Physics in Medicine \& Biology, 55, R1-R63. https://doi.org/10.1088/0031-9155/55/5/R01

[2] Kawamura, H., Sakae, T., Terunuma, T., Ishida, M., Shibata, Y. and Matsumura, A. (2013) Evaluation of Three-Dimensional Polymer Gel Dosimetry Using X-Ray CT and R2 MRI. Applied Radiation and Isotopes, 77, 94-102. https://doi.org/10.1016/j.apradiso.2013.02.011

[3] Ceberg, S., Gagne, I., Gustafsson, H., Scherman, J.B., Korreman, S.S., Kjaer-Kristoffersen, F., Hilts, M. and Bäck, S.A. (2010) Rapid Arc Treatment Verification in 3D Using Polymer Gel Dosimetry and Monte Carlo Simulation. Physics in Medicine \& Biology, 55, 4885-4898. https://doi.org/10.1088/0031-9155/55/17/001

[4] Novotný, J., Dvorák, P., Spevácek, V., Tintera, J., Novotný, J., Cechák, T. and Liscák, R. (2002) Quality Control of the Stereotactic Radiosurgery Procedure with 
the Polymer-Gel Dosimetry. Radiotherapy and Oncology, 63, 223-230. https://doi.org/10.1016/S0167-8140(02)00064-6

[5] Hayashi, N., Malmin, R.L. and Watanabe, Y. (2014) Dosimetric Verification for Intensity-Modulated Arc Therapy Plans by Use of 2D Diode Array, Radiochromic Film and Radiosensitive Polymer Gel. Journal of Radiation Research, 55, 541-552. https://doi.org/10.1093/jrr/rrt139

[6] De Deene, Y., De Wagter, C., Van Duyse, B., Derycke, S., De Neve, W. and Achten, E. (1998) Three-Dimensional Dosimetry Using Polymer Gel and Magnetic Resonance Imaging Applied to the Verification of Conformal Radiation Therapy in Head-and-Neck Cancer. Radiotherapy and Oncology, 48, 283-291.

https://doi.org/10.1016/S0167-8140(98)00087-5

[7] De Deene, Y., Vergote, K., Claeys, C. and De Wagter, C. (2006) The Fundamental Radiation Properties of Normoxic Polymer Gel Dosimeters: A Comparison between a Methacrylic Acid Based Gel and Acrylamide Based Gels. Physics in Medicine \& Biology, 51, 653-673. https://doi.org/10.1088/0031-9155/51/3/012

[8] Maryanski, M.J., Audet, C. and Gore, J.C. (1997) Effects of Crosslinking and Temperature on the Dose Response of a BANG Polymer Gel Dosimeter. Physics in Medicine \& Biology, 42, 303-311. https://doi.org/10.1088/0031-9155/42/2/004

[9] Scheib, S.G., Schenkel, Y. and Gianolini, S. (2004) Absolute Dose Verifications in Small Photon Fields Using BANG ${ }^{\mathrm{m}}$ Gel. Journal of Physics. Conference Series, 3, 228-231. https://doi.org/10.1088/1742-6596/3/1/034

[10] Spevacek, V., Novotny, J.Jr., Dvorak, P., Novotny, Jr., Vymazal, J. and Cechak. T. (2001) Temperature Dependence of Polymer-Gel Dosimeter Nuclear Magnetic Resonance Response. Medical Physics, 28, 2370-2378. https://doi.org/10.1118/1.1410124

[11] Hrbacek, J., Spevacek, V., Novotny, Jr. and Cechak, T. (2004) A Comparative Study of Four Polymer Gel Dosimeters. Journal of Physics: Conference Series, 3, 150-154. https://doi.org/10.1088/1742-6596/3/1/015

[12] Fuse, H., Shinoda, K., Inohira, M., Kawamura, H., Miyamoto, K., Sakae, T. and Fujisaki T. (2015) Utilization of Polymer Gel as a Bolus Compensator and a Dosimeter in the Near-Surface Buildup Region for Breast-Conserving Therapy. Review of Scientific Instruments, 86, Article ID: 096103. https://doi.org/10.1063/1.4930554

[13] Kawamura, H., Shinoda, K., Fuse, H., Terunuma, T., Miyamoto, K., Sakae, T. and Matsumura, A. (2013) Comparison between Polymer Gel Dosimetry and Calculated Dose with Small Field in Stereotactic Irradiation. Journal of Physics. Conference Series, 444, Article ID: 012031. https://doi.org/10.1088/1742-6596/444/1/012031

[14] Vandecasteele, J. and De Deene, Y. (2013) On the Validity of 3D Polymer Gel Dosimetry: III. MRI-Related Error Sources. Physics in Medicine \& Biology, 58, 63-85. https://doi.org/10.1088/0031-9155/58/1/63

[15] Murakami, Y., Nakashima, T., Watanabe, Y., Akimitsu, T., Matsuura, K., Kenjo, M., et al. (2007) Evaluation of the Basic Properties of the BANGkit Gel Dosimeter. Physics in Medicine \& Biology, 52, 2301-2311. https://doi.org/10.1088/0031-9155/52/8/017

[16] Mamisch, T.C., Trattnig, S., Quirbach, S., Marlovits, S., White, L.M. and Welsch, G.H. (2010) Quantitative T2 Mapping of Knee Cartilage: Differentiation of Healthy Control Cartilage and Cartilage Repair Tissue in the Knee with Unloading-Initial Results. Radiology, 254, 818-826. https://doi.org/10.1148/radiol.09090335

[17] Nelson, T.R. and Tung, S.M. (1987) Temperature Dependence of Proton Relaxation 
Times in Vitro. Magnetic Resonance Imaging, 5, 189-199.

https://doi.org/10.1016/0730-725X(87)90020-8

[18] Bloembergen, N., Purcell, E.M. and Pound, R.V. (1948) Relaxation Effects in Nuclear Magnetic Resonance Absorption. Physical Review, 73, 679-721.

https://doi.org/10.1103/PhysRev.73.679

[19] Gore, J.C., Kang, Y.S. and Schulz, R.J. (1984) Measurement of Radiation Dose Distributions by Nuclear Magnetic Resonance (NMR) Imaging. Physics in Medicine \& Biology, 29, 1189-1197. https://doi.org/10.1088/0031-9155/29/10/002

[20] De Deene, Y. and De Wagter, C. (2001) Artefacts in Multi-Echo T2 Imaging for High-Precision Gel Dosimetry: III. Effects of Temperature Drift during Scanning. Physics in Medicine \& Biology, 46, 2697-2711.

https://doi.org/10.1088/0031-9155/46/10/312 